\title{
PROCEDIMENTOS HEURÍSTICOS NO PROCESSAMENTO LINGUÍSTICO? UM ESTUDO SOBRE A INTERPRETAÇÃO DE EXPRESSÕES QUANTIFICADAS NO PB
}

\author{
¿PROCEDIMIENTOS HEURÍSTICOS EN EL PROCESAMIENTO LINGÜÍSTICO? UN ESTUDIO SOBRE LA \\ INTERPRETACIÓN DE EXPRESIONES CUANTIFICADAS EN PB
}

\section{HEURISTICS PROCEDURES IN LANGUAGE PROCESSING? A STUDY ON THE INTERPRETATION OF QUANTIFIED EXPRESSIONS IN BP}

\author{
Erica dos Santos Rodrigues* \\ Pontifícia Universidade Católica do Rio de Janeiro - PUC-Rio, LAPAL, BR \\ Mercedes Marcilese \\ Universidade Federal de Juiz de Fora - UFJF, NEALP, BR
}

\begin{abstract}
RESUMO: O presente artigo faz parte de uma pesquisa mais ampla sobre a interpretação preferencial - coletiva ou distributiva atribuída a expressões contendo os quantificadores universais cada, todo e todos no português brasileiro (PB). Este trabalho traz uma revisão dos resultados de estudos prévios e reporta dois novos experimentos de compreensão, nos quais é explorado o papel do contexto prévio na compreensão de expressões quantificadas. Os resultados experimentais são discutidos à luz de propostas segundo as quais, durante o processamento linguístico, o parser pode ser orientado por estratégias heurísticas, não sendo guiado apenas por procedimentos estritamente algorítmicos/estruturais. É ponderado ainda em que medida a profundidade do processamento conduzido pode ser afetada pela situação experimental específica - levando em consideração o tipo de tarefa a ser realizada pelos participantes e as informações prévias disponíveis - e pode ter, como consequência, reflexos no tipo de interpretação associada às expressões quantificadas.

PALAVRAS-CHAVE: processamento linguístico; procedimentos heurísticos; expressões quantificadas; português brasileiro.
\end{abstract}

RESUMEN: El presente artículo forma parte de una investigación más amplia que tiene como objetivo evaluar las interpretaciones preferenciales - colectivas o distributivas - atribuidas a expresiones formadas por los cuantificadores universales cada, todo y todos en portugués brasileño (PB). Este trabajo contempla una revisión de resultados previos y reporta dos nuevos experimentos en los cuales analizamos el papel del contexto previo para la interpretación de esas expresiones. Discutimos los resultados experimentales en el marco de propuestas de acuerdo con las cuales, durante el procesamiento lingüístico, el parser podría ser orientado por estrategias heurísticas y no sólo por procesos estrictamente algorítmicos/estructurales. Analizamos también en qué medida la profundidad del procesamiento efectuado puede ser afectada por la situación experimental específica - teniendo en cuenta el tipo de tarea a ser realizada y las informaciones previas disponibles - y, consecuentemente, puede tener reflejos en el tipo de interpretación asociada a las expresiones cuantificadas.

PALABRAS CLAVE: procesamiento lingüístico; procedimientos heurísticos; expresiones cuantificadas; portugués brasileño.

ABSTRACT: This paper is part of a broader study about the preferred interpretation - collective or distributive - attributed to expressions containing the universal quantifiers cada ('each'), todo and todos ('every' and 'all') in Brazilian Portuguese (BP). We review the results of previous studies and report two new experiments designed with the objective of investigating the role of previous context in the comprehension of quantified expressions. The experimental results are discussed in the light of heuristic approaches to language processing and we assume that the parser is not strictly guided by algorithmic/structural procedures. We also investigate in which extent the depth of the driven processing can be affected by the specific experimental situation - taking into account the type of task and the availability of previous information. The possibility that these factors affect the interpretation of the quantified expressions is also evaluated.

KEYWORDS: linguistic processing; heuristic procedures; quantified expressions; Brazilian Portuguese.

\section{INTRODUÇÃO}

A interpretação de expressões quantificadas (doravante, expressões-Q) é um tópico de investigação na interface sintaxe-semântica que tem mobilizado o interesse de pesquisadores tanto na área de teoria linguística quanto na de processamento de sentenças. As preferências de escopo vinculadas à compreensão desse tipo de expressões têm sido largamente investigadas no âmbito da Psicolinguística e, principalmente,

*Emails: ericasr@puc-rio.br; mmarcilese@gmail.com. 
no contexto de pesquisas sobre a aquisição da linguagem (PHILLIP 1995; CRAIN et al. 1996, ROEPER, STRAUSS; PEARSON 2006; dentre outros).

Em sentenças contendo expressões-Q como (1), nas quais o escopo do quantificador universal (Q) é potencialmente ambíguo, duas interpretações - representadas em (2) e (3) - seriam possíveis. Na situação ilustrada em (2), existem várias palmeiras e para cada palmeira existe um macaco que subiu em alguma delas; já em (3), existe uma única palmeira e todo macaco subiu na mesma palmeira. A primeira interpretação também é denominada leitura de escopo superficial, enquanto a segunda é chamada de leitura de escopo invertido.

(1) Every monkey climbed a palm.

Q-universal macaco subiu Q-existencial palmeira.

(2) Leitura de escopo superficial

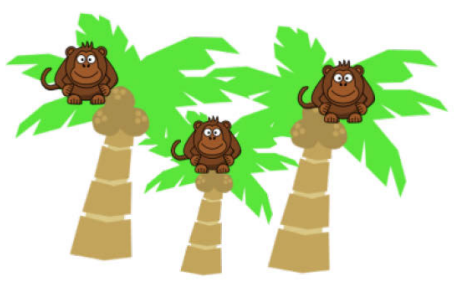

(3) Leitura de escopo invertido

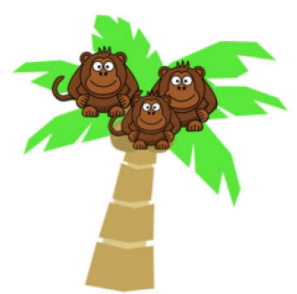

A interpretação de escopo superficial corresponde à ordem linear dos Qs na sentença, já uma interpretação de escopo invertido é aquela na qual os dois Qs seriam interpretados numa ordem inversa à da sequência linear. Essa segunda interpretação pode ser chamada de leitura singular ou coletiva, enquanto a primeira possibilidade constituiria uma leitura plural ou distributiva. As leituras ilustradas em (2) e (3) podem ser representadas de acordo com a notação empregada em (4) e (5) respectivamente.

$(4)(\forall x)(x$ é um macaco $(\exists y)$ (y é uma palmeira \& x subiu y))

["Para cada macaco $x$, existe uma palmeira $y$, tal que x subiu $y$ "]

(5) $(\exists y)$ (y é uma palmeira \& $(\forall x)$ (x é um macaco, x subiu y))

["Existe uma palmeira $y$, tal que para cada macaco, $x, x$ subiu $y$ "]

Uma explicação frequente para essas diferentes intepretações é formulada com base na ideia de um alçamento do Q, isto é, uma operação de movimento do Q-existencial ou indefinido, que ocorreria na Forma Lógica, ou seja, se trataria de uma operação que não ocorreria na sintaxe aberta. Pelo fato de se tratar de uma caracterização eminentemente teórica, uma questão relacionada que pode ser levantada - em termos de processamento - é, em que medida, uma dessas interpretações seria mais simples ou automática do que a outra e, ainda, se $Q$ específicos teriam leituras preferencialmente associadas. Existem preferências claras no que diz respeito a uma possível leitura default para esses elementos? Em que medida diferentes leituras associadas aos Qs decorreriam do modo específico como o processador linguístico opera (com base principalmente em algoritmos ou aceitando a atuação de heurísticas)?

Neste trabalho, nos voltamos especificamente para a análise de expressões-Q do tipo cada + NP singular, todo + NP singular e todos + DP plural, buscando verificar os tipos de leitura que lhe são atribuídos (contrastando interpretações coletivas vs. distributivas) e o papel que um contexto prévio, favorecendo uma dada leitura, desempenha nesse processo. Trata-se de um estudo que integra uma pesquisa mais ampla em que se tem examinado como essas expressões são interpretadas em diferentes situações experimentais, envolvendo técnicas e procedimentos metodológicos distintos.

O artigo está assim organizado: na seção 2 introduzimos a ideia de um parser linguístico orientado por heurísticas, apresentando algumas das propostas levantadas no âmbito dos estudos do processamento da linguagem nesse sentido; na mesma seção discutimos resultados experimentais que se mostram compatíveis com a hipótese da implementação de procedimentos heurísticos nas etapas iniciais de processamento de expressões-Q; a seção 3 é dedicada a uma revisão da caracterização teórica sobre as expressões-Q do PB 
focalizadas na presente pesquisa, bem como de resultados experimentais obtidos em estudos prévios; na seção 4 são reportados dois novos experimentos que buscam avaliar o papel do contexto prévio na interpretação de expressões-Q; por último, concluímos com uma discussão acerca de como os diferentes resultados experimentais obtidos podem ser analisados à luz de uma abordagem que considera que o que é solicitado em cada tipo de tarefa pode levar o participante a se engajar em um modo de processamento específico (de caráter mais algorítmico ou heurístico), o que, por sua vez, pode requerer uma análise mais ou menos superficial dos estímulos linguísticos, com reflexos no tipo de leitura preferencial atribuída à expressão-Q.

\section{UM PARSER ORIENTADO POR HEURÍSTICAS? MODELOS TEÓRICOS E EVIDÊNCIAS EXPERIMENTAIS}

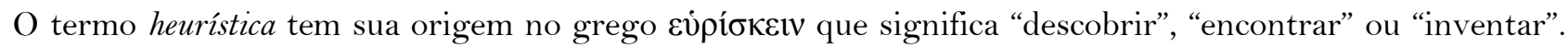
Heurísticas consistem em estratégias para enfrentar situações problemáticas, ou regras de cunho mais geral, baseadas principalmente na experiência e que permitem produzir uma resposta aproximada frente a um dado problema ou tomar uma decisão. Heurísticas constituem "regras imperfeitas", podem ser mais ou menos explícitas e são implementadas frequentemente em diversos domínios da cognição e práticas humanas (FISCHHOFF, 1999, p.423-425).

O estudo dos procedimentos heurísticos ganhou espaço no âmbito da Psicologia Cognitiva principalmente a partir dos estudos de Tversky e Kahneman (1971, 1974, dentre outros). Esses autores defendem a ideia de que a realização de julgamentos em condições de incerteza costuma requerer soluções de natureza heurística. Nessas situações, os sujeitos não têm acesso à informação ou conhecimento requerido para fornecer respostas mais precisas e, por esse motivo, acabam se baseando em heurísticas para resolver situações problemáticas.

Um dos procedimentos heurísticos estudados por Tversky e Kahneman (1971) consiste na expectativa de que observações relativas a eventos passados possam servir para prever situações futuras. Os autores exploraram essa tendência a partir de experimentos tomando como sujeitos psicólogos acostumados a trabalhar com metodologia quantitativa. Os participantes superestimaram a probabilidade de que amostras pequenas pudessem trazer evidências favoráveis às suas hipóteses de pesquisa, e propuseram projetos de investigação com poder estatístico significativamente baixo. Embora cientistas bem treinados certamente sejam capazes de avaliar de forma correta o poder das suas análises, para que isso aconteça eles devem primeiro perceber que seus julgamentos baseados em heurísticas são incorretos. Em trabalhos subsequentes, os autores caracterizaram essa tendência como uma heurística mais geral denominada representatividade (representativeness). Os sujeitos utilizam essa estratégia para avaliar a probabilidade de ocorrência de um certo evento a partir da forma na qual esse evento capta as propriedades mais relevantes do processo que o produz. Embora seja bastante útil, essa estratégia pode levar a uma série de erros, a menos que o sujeito disponha de uma amostra de informação prévia suficientemente grande.

Outras duas heurísticas exploradas pelos autores são a disponibilidade (availability) e a ancoragem e ajuste (anchoring and adjustment). Empregar uma estratégia baseada em disponibilidade consiste em julgar um evento como provável na medida que é possível se lembrar de exemplos do mesmo ou imaginar tal evento acontecendo. Essa heurística pode conduzir a um viés caso as instâncias de um certo evento sejam (in)disponíveis de forma não equilibrada na memória do sujeito. Uma estratégia baseada em ancoragem $e$ ajuste, por sua vez, envolve estimar uma probabilidade partindo de um valor inicialmente determinado e calculando o quanto ela pode ser maior ou menor. Frequentemente, as pessoas apresentam uma tendência a "ajustar" muito pouco, ficando presas da ancoragem inicial. Assim, caso a ancoragem inicial tenha sido inadequada e os ajustes posteriores insuficientes, o sujeito corre o risco de realizar um julgamento enviesado.

Embora procedimentos heurísticos sejam empregados com frequência na condução de raciocínio, na resolução de tarefas e na tomada de decisões, não é claro em que medida esse tipo de estratégia teria um papel em outros processos cognitivos, por exemplo, no processamento da linguagem. No âmbito dos estudos sobre o processamento de sentenças, a caracterização do parser linguístico como sendo de natureza algorítmica tem uma larga tradição na literatura (FRAZIER; FODOR, 1978; FRAZIER, 1979; FRAZIER; RAYNER, 1982). Um algoritmo - termo muitas vezes tomado como antônimo de heurística - representa 
uma sequência de passos, um método ou técnica para realizar alguma tarefa. A principal característica de um algoritmo é o fato de ser formado por um conjunto finito de regras, passos/etapas ou operações não ambíguas que podem ser seguidas de modo a se obter um resultado. Essa lista de operações pode ser aplicada mecânica e sistematicamente a um conjunto de símbolos (tokens) ou objetos (Ex. configurações das peças num tabuleiro de xadrez, números, os ingredientes de uma receita de bolo, etc.) (DIETRICH, 1999, p.11-12).

Towsend e Bever (2001) trazem uma perspectiva que confronta visões algorítmicas do processador linguístico, ao levantarem a possibilidade de que o funcionamento do parser seja, em alguma medida, orientado por heurísticas e estratégias. Baseados em abordagens de análise pela síntese, originalmente propostas no âmbito da percepção da fala, Bever e Townsend consideram que nós compreendemos 'duas vezes', no sentido de que:

a quick-and-dirty parse is initially elicited. (...) This preliminary analysis uses a variety of surface schemata (...) to organize an initial hypothesis about meaning. From that, a complete parse may be accessed that computes a derivation and fills in the remaining syntactic details. (2001, p. 163).

De acordo com essa visão, durante a compreensão, o parser utilizaria uma série de heurísticas baseadas em templates que levam em consideração informações de cunho probabilístico, mas que estariam relacionadas com as restrições gramaticais de forma indireta. Uma questão que se coloca é como é feito esse processo de atribuição de uma estrutura sintática inicial à sentença. Uma possibilidade é que informação de natureza semântica, ligada aos papéis temáticos de palavras e sintagmas, restrinja o espaço inicial de busca de estruturas sintáticas potenciais a serem atribuídas a uma dada sequência. O modelo de Towsend e Bever prevê dois níveis de representação que são computados de modo independente, em estágios distintos. Há um primeiro estágio "pseudo-sintático", em que um significado provável é atribuído ao input linguístico. Nesse estágio, observam-se processos de reconhecimento lexical e atribuição de categorias, seguidos da segmentação da sequência linguística em sintagmas, com identificação dos núcleos e estabelecimento de relações argumentais prováveis entre os núcleos dos sintagmas principais. Um segundo estágio, chamado de sintaxe real, gera uma estrutura sintática baseada na análise inicial e checa o output em relação ao input original. $\mathrm{O}$ que é definido no estágio pseudo-sintático estabelece restrições quanto às estruturas sintáticas iniciais selecionadas pela gramática.

De acordo com os autores, tomando-se o modelo de gramática proposto no âmbito do Programa Minimalista da Teoria Gerativa, pode-se considerar que a representação computada no primeiro estágio poderia vir a compor a chamada numeração para uma dada derivação sintática. O resultado dessa derivação geraria uma descrição sintática totalmente especificada. Essa representação, por sua vez, seria pareada com o input original e, no caso de correspondência, a computação terminaria. No caso de incompatibilidade, a computação poderia ser reiniciada, processos de revisão seriam acionados.

Situações nas quais a interpretação linguística parece se afastar das restrições da gramática são tomadas como evidências favoráveis a essa visão do funcionamento do parser. Informação de cunho probabilístico teria um papel importante na compreensão da fala espontânea, a qual é marcada por lapsos, falsos começos, erros de pronúncia, etc. Segundo os autores: "Any model that depends on completely recognizable wellformed units will not be adequate to the normal task of comprehension" (2001, p.159).

Em uma abordagem semelhante à de Towsend e Bever (2001), Ferreira e colaboradores (FERREIRA, BAILEY; FERRARO, 2002; FERREIRA, 2003; FERREIRA; PATSON, 2007; CHRISTIANSON et al., 2001) têm proposto que as representações geradas no processo de compreensão podem não ser representações detalhadas, completas dos enunciados produzidos pelo falante. Segundo Ferreira, "the system's responsability is to create representations that are suitable for the task that the listener wants to perform with the help of the linguistic input." (2007, p. 71). Nesse sentido, as representações criadas pelo sistema de compreensão poderiam ser apenas good enough. Referindo-se especificamente às situações de fala espontânea, de diálogo, a autora comenta que fatores associados ao curso temporal das sentenças em um diálogo (uma sentença seguindo-se à outra rapidamente) poderiam fazer com que o sistema não tivesse tempo para considerar todas as fontes relevantes de informação e, assim, computar uma estrutura detalhada 
para cada sentença; seriam, então, geradas estruturas do tipo good enough, que seriam refinadas se necessário. ${ }^{1}$

São apresentadas como evidências de que as pessoas nem sempre criam representações detalhadas das sentenças o fato de frequentemente terem uma compreensão superficial do significado das mesmas. De modo a ilustrar esse ponto, Ferreira cita o exemplo de respostas dada à pergunta How many of each type of animal did Moses take on the ark? (Quantos animais de cada tipo Moisés levou na arca?). As pessoas, em geral, não notam que foi feita referência a Moisés (no lugar de Noé) e respondem “dois”. Isso é similar ao que ocorre com sentenças como Where should the authorities bury the survivors? (Onde as autoridades devem enterrar os sobreviventes?), em que as pessoas parecem não perceber a anomalia. Na mesma linha de exemplos, Ferreira menciona um estudo de Frazier, Pacht e Rayner (1999), em que dada uma frase que poderia receber tanto uma leitura distributiva quanto coletiva como em Mary and John saved \$100 (Maria e João economizaram \$100), as pessoas não aderem a uma das interpretações inicialmente; elas apenas o fazem quando informação apresentada em porção subsequente do tex to delimita uma dada interpretação.

Também têm sido reportados como evidência de processamento good enough resultados concernentes ao modo como as pessoas compreendem garden-path sentences (sentenças-labirinto) (CHRISTIANSON et al. 2001; FERREIRA et al. 2002). Dada uma sentença do tipo While Mary bathed the baby played in the crib (Enquanto Maria dava banho no bebê brincava no berço) ${ }^{2}$, foi verificado que as pessoas nem sempre compreendiam corretamente a sentença e respondiam "sim” quando perguntadas se Maria havia dado banho no bebê. De acordo com Christianson et al. (2001), nem sempre a interpretação final de uma sentença corresponde ao que seria esperado com base em sua estrutura sintática; é, possível, por exemplo, que persista uma análise inicial incorreta enquanto uma análise final correta é construída. Para o autor, "the goal of language processing is not always to create an idealized structure, but rather to create a representation that is 'good enough' to satisfy the comprehender that an appropriate interpretation has been obtained” (p. 368). Compatível com essa ideia de processamento superficial, também tem-se resultados de experimentos envolvendo a leitura de sentenças passivas implausíveis como The dog was bitten by the man (O cachorro foi mordido pelo homem) (FERREIRA, 2003). Assumindo-se o que seria proposto por Bever (1970) e Townsend e Bever (2001), os participantes, de forma heurística, usariam uma espécie de template de sentença declarativa ao processar essa sentença e a "leriam" como equivalente a The man was bitten by a dog. De acordo com Ferreira e Patson (2007), a interpretação heurística poderia ser selecionada ou porque ela está mais prontamente disponível ou porque o sistema tem algum motivo para preferi-la (por exemplo, o fato de tal interpretação se conformar com o conhecimento sobre o mundo real).

Estudos com potenciais relacionados a evento (ERP) têm sido apresentados como suporte para a hipótese de que o sistema de compreensão se baseia em processos heurísticos. Ferreira e Patson (2007) citam, por exemplo, o trabalho de van Herten et al. (2005), em que sentenças com anomalias semânticas teriam eliciado efeitos de P600 (em geral associados a processos sintáticos) e não efeitos de N400, um potencial associado à sensibilidade a fatores semânticos (KUTAS; HILLYARD, 1980, 1983). Resultados similares são também reportados por Kim e Osterhout (2005). Assim, dada uma frase como The hearty meal was devouring the kids (A refeição saudável estava devorando as crianças), um processamento inicial de natureza heurística, de composição semântica, seria responsável pela atribuição de uma interpretação plausível da sentença, donde a não observação de um efeito N400. ${ }^{3} \mathrm{Em}$ um momento posterior, quando se verificasse uma incongruência entre essa intepretação e aquela que poderia ser atribuída dada a estrutura sintática

\footnotetext{
${ }^{1}$ Ferreira \& Patson (2007) observam que situações experimentais - seja pelo tipo de tarefa, como por exemplo, responder a perguntas de compreensão, ou pela própria natureza da situação - poderiam levar o participante a se engajar em um modo de processamento mais "pesado", com vistas a gerar uma interpretação única e definitiva para a sentença sendo processada. Não se pode, contudo, estender esse tipo de observação para todas as situações experimentais. Conforme será discutido nas próximas seções, o próprio tipo de tarefa experimental e demandas temporais associadas podem vir a fazer com que o participante engaje em modos de processamento distintos.

${ }^{2}$ Um exemplo equivalente em português que poderia gerar um efeito labirinto seria "Enquanto Maria costurava as meias caíram no chão", em que o parser inicialmente concatena "as meias" a "costurava" e depois reanalisa a estrutura ao verificar que se trata de sujeito do verbo da oração seguinte. Para um conjunto de trabalhos sobre esse tópico, remetemos ao artigo de Ribeiro (2012).

${ }^{3}$ Ferreira \& Patson (2007), comentam que há uma questão importante que ainda não foi considerada nos trabalhos que têm explorado a abordagem good enough - qual seja, se implausibilidade é processada diferentemente de anomalia semântica. A esse respeito, citam um estudo de movimento ocular durante a leitura, conduzido por Rayner et al. (2005). Nesse trabalho, a partir do contraste de sentenças como John used a pump to inflate the large carrots for dinner. (anômala)/John used an axe to chop the large carrots for dinner (implausível)/ John used a knife to chop the large carrots for dinner (sentença controle plausível), os autores concluem que quando uma palavra é anômala ela tem um efeito imediato nos movimentos oculares, mas que o mesmo não se observa nos casos de implausibilidade.
} 
correspondente à forma superficial da sentença, a anomalia poderia ser percebida como uma incompatibilidade de ordem sintática, eliciando um P600. ${ }^{4}$

Ferreira (2003; FERREIRA; PATSON, 2007) aproxima seu programa de pesquisa de estudos sobre tomada de decisão (TVERSKY; KAHNEMAN, 1974). A autora faz referência a trabalhos sobre racionalidade limitada (bounded rationality) e heurísticas de julgamento (GIGERENZER et al. 1999 apud FERREIRA 2003), nos quais se assume que, em especial em condições de alta demanda, o organismo lança mão de heurísticas rápidas e frugais ("fast and frugal heuristics") no lugar de algoritmos, pois, embora estes levem a uma solução correta, são ao mesmo tempo excessivamente custosos para serem implementados/empreendidos.

No que tange especificamente a estudos com expressões- $Q$, foco deste artigo, até onde se tem conhecimento são poucos os trabalhos em que se busca articular explicitamente questões relativas ao modo de funcionamento do parser e a interpretação atribuída a esses elementos.

De acordo com Tunstall (1998), embora pesquisas sobre o modo como adultos interpretam sentenças com diferentes relações de escopo entre Qs sejam conduzidas desde a década de 70, trabalhos com um caráter experimental, envolvendo situações mais naturais de leitura e compreensão, passam a ser conduzidos apenas na década de 90, com destaque para Gillen (1991) e, em especial Kurtzman e MacDonald (1993), estes últimos os primeiros a publicarem resultados de ordem temporal sobre interpretação de sentenças com interação de Qs.

Kurtzman e MacDonald (1993) pesquisam o processamento de relações de escopo entre Qs no âmbito de uma investigação mais ampla acerca do processamento de estruturas ambíguas. Os autores focalizam o papel que a posição estrutural das expressões-Q tem na atribuição de uma dada interpretação da sentença. Adotando uma terminologia empregada comumente em trabalhos sobre processamento de sentenças ambíguas (FRAZIER; FODOR, 1978), os autores buscam verificar que princípios guiariam decisões iniciais do parser quanto a relações de escopo entre Qs. Para fins deste artigo, faremos referência apenas aos resultados do processamento de sentenças com o Q-every (Every kid climbed a tree). Foram verificadas preferências de leitura dessas sentenças (distributiva/coletiva) em duas condições experimentais distintas: ambígua e não-ambígua:

$\begin{array}{lll} & \text { Ambigua } & \text { Não ambígua } \\ \text { Retomada NP plural } & \begin{array}{l}\text { Every kid climbed a tree. The } \\ \text { trees were full of apples. } \\ \text { (escopo linear) }\end{array} & \begin{array}{l}\text { Every kid climbed a different } \\ \text { apples. }\end{array} \\ \text { Retomada NP singular } & \begin{array}{l}\text { Every kid climbed a tree. The } \\ \text { tree was full of apples. } \\ \text { (escopo invertido) }\end{array} & \begin{array}{l}\text { Every kid climbed the same } \\ \text { tree. The tree was full of } \\ \text { apples. }\end{array}\end{array}$

Entre os vários resultados reportados, destaca-se aqui a preferência por uma continuação plural na condição com ambiguidade. Esse efeito de facilitação de retomada por NP anafórico no plural é compatível com uma preferência por uma leitura distributiva, correspondente a uma relação de escopo linear entre os Qs.

Dwivedi et al. (2010) apontam dois aspectos problemáticos no estudo de Kurtzman e MacDonald (1993). Primeiro, o fato de a tarefa requerer um julgamento de natureza metalinguística; nesse sentido, não refletiria processos inconscientes, em tempo real; e o fato de os julgamentos ocorrerem apenas depois que a

\footnotetext{
${ }^{4}$ Em relação aos resultados, em particular do trabalho de Kim \& Ostherhout (2005), cumpre registrar as objeções apresentadas em Phillips (2012), a partir de resultados obtidos em um conjunto de estudos realizados com falantes de inglês, espanhol e chinês, os quais, segundo ele, permitem questionar a ideia de que ocorreria um processo de composição semântica independente.
} 
segunda sentença inteira havia sido lida, o que não permitiria verificar decisões iniciais relativas ao parsing dessas estruturas. Somado a isso, observam que os tempos de reação não foram considerados ${ }^{5}$

Dwivedi et al. (2010) observam que há resultados conflitantes na literatura no que tange a uma preferência geral por leituras compatíveis com escopo linear, fato que poderia ser atribuído à investigação simultânea de vários fatores linguísticos, tais como tipo de sintagma verbal, tipo de $Q$, ordem dos Qs nos estímulos, além de não ter sido utilizada uma condição controle não ambígua em alguns estudos.

Tendo isso em vista, Dwivedi et al. (2010) conduziram um experimento em que, com o objetivo de traçar o curso temporal da interpretação na segunda sentença (que permite desambiguizar a primeira), registraram os potenciais relacionados a eventos (ERPs) nas seguintes posições da segunda sentença - no nome, no verbo, após o verbo. Os estímulos experimentais eram semelhantes aos usados no experimento 1 de Kurtzman e MacDonald (1993), com "every" na posição de sujeito e "a" na posição de objeto direto. A primeira sentença era apresentada inteira na tela; na segunda sentença, cada palavra era apresentada separadamente por $300 \mathrm{~ms}$, com um intervalo de $300 \mathrm{~ms}$ entre os estímulos. ${ }^{6}$

Os pesquisadores não encontraram evidências eletrofisiológicas indicativas de uma preferência por uma continuação singular ou plural da primeira sentença. A ambiguidade não seria imediatamente resolvida, isto é, as construções envolvendo as expressões- $Q$ ficariam subespecificadas até o ponto em que informação desambiguizadora ocorresse na sentença - no caso, na posição do NP anafórico e do verbo flexionado. Esse resultado é, segundo os autores, compatível com uma abordagem good enough, segundo a qual processos interpretativos são em geral incompletos e superficiais; os falantes não se comprometeriam com um significado particular durante o parsing. Haveria, contudo, um custo posterior desse processamento superficial, associado à integração do NP anafórico na segunda sentença, que demandaria maior alocação de recursos cognitivos. ${ }^{7}$

A despeito de a ideia de que processos heurísticos atuam na compreensão de sentenças já encontrar suporte em vários trabalhos, um tópico que ainda carece de investigação diz respeito ao modo como o produto de procedimentos heurísticos se coordena com o output de algoritmos sintáticos. Ferreira (2003) deixa claro que até aquele momento os resultados dos experimentos não permitiam responder a esta questão. A autora aponta três possibilidades a serem consideradas: se heurísticas e algoritmos ocorreriam em paralelo, se as heurísticas seriam empregadas apenas quando os algoritmos se tornassem difíceis de aplicar, ou se os algoritmos seriam usados apenas quando se perdesse confiança na intepretação criada a partir de heurísticas.

Dwivedi (2013) aborda essa questão, ao contrastar resultados de três experimentos de leitura automonitorada, envolvendo as mesmas sentenças ambíguas com os Qs "every" e "a", seguidas de continuações com NP singular e NP plural. Os experimentos se diferenciavam em termos dos seguintes fatores: viés léxico-pragmático e demanda da tarefa.

Com vistas a examinar possível efeito léxico-pragmático, nos experimentos 1 e 2 os estímulos críticos apresentavam um viés (bias) para retomada por um NP plural (interpretação de escopo linear). Os estímulos foram selecionados de um estudo off-line prévio (ver DWIVEDI et al. 2010), no qual foi verificado que alguns itens apresentavam um forte viés em uma das alternativas possíveis. Em termos da demanda da tarefa, nos experimentos 2 e 3 , de modo a poder fazer o participante engajar em um processamento mais profundo, este precisava responder a questões explícitas após a leitura. O esquema a seguir, adaptado de Dwivedi (2013), fornece uma visão geral dos experimentos:

\footnotetext{
${ }^{5}$ As sentenças eram apresentadas inteiras na tela de um computador mediante o pressionar da barra de espaço. Os participantes indicavam por meio de teclas de SIM e NÃO se a segunda sentença fazia sentido ou constituía uma continuação natural para a primeira.

6 Segundo os autores, essa forma de apresentação minimizava possíveis efeitos de movimento ocular no registro do EEG e possibilitava a sincronização entre o registro do EEG com a apresentação de cada palavra.

${ }^{7}$ Para detalhamento dos resultados de ERPs e sua interpretação, ver o artigo original.
} 


$\begin{array}{lll}\text { Experimento } & \text { Viés léxico-pragmático } & \text { Demanda da tarefa } \\ 1 & \text { Sim } & \text { Não } \\ 2 & \text { Sim } & \text { Sim } \\ 3 & \text { Não } & \text { Sim }\end{array}$

A opção por um experimento de leitura auto-monitorada é justificada pela autora pelo fato de este método não impor restrições ao tempo de apresentação dos estímulos, permitindo investigar como se daria o curso temporal de processos heurísticos e algorítmicos. ${ }^{8}$ No experimento de Dwivedi et al. 2010, embora tenha sido empregado o método de ERPs, o qual é reconhecido por prover informação temporal acurada sobre os processos cognitivos, a taxa padrão de apresentação de palavras nos experimentos é bastante lenta, entre 300-600ms por palavra. Segundo a autora, considerando-se que processos heurísticos léxico-pragmáticos poderiam ocorrer muito rapidamente, a taxa lenta de apresentação dos estímulos nos experimentos com ERP não permitiria distinguir processamento estratégico e algorítmico. Consequentemente, o processamento poderia se apresentar como paralelo e interativo, quando na verdade poderia não ser.

Segundo Dwivedi, os resultados do conjunto dos três experimentos sugerem que o processamento de sentenças requer tanto processos heurísticos quanto algorítmicos e que aqueles precedem a fase relativa à computação algorítmica. Enquanto o experimento 1 permitiu demonstrar que as sentenças são processadas de forma superficial, como sugerido na abordagem good enough, no experimento 2 , que requeria um processamento mais profundo por conta da tarefa de compreensão, os resultados do tempo de leitura foram consistentes com uma interpretação léxico pragmática e as respostas às perguntas de interpretação foram compatíveis com uma computação algorítmica das relações de escopo. O experimento 3, cujos estímulos não eram enviesados no sentido de uma dada leitura, mas que apresentavam pergunta de compreensão, apresentou o mesmo padrão de resultados do experimento 2. A conclusão da autora é que processos algorítmicos, sensíveis a aspectos estruturais, ocorreriam apenas quando requeridos no processamento de sentenças ambíguas em termos de escopo de Qs.

Neste trabalho, buscamos nos aproximar da discussão acerca de processos heurísticos e algorítmicos a partir do contraste entre os resultados de dois novos experimentos com Qs e resultados de experimentos prévios por nós conduzidos. Como será visto, nos dois experimentos a serem apresentados na seção 4 , foi construído um contexto prévio que direciona uma possível interpretação das sentenças com Qs (coletiva ou distributiva). Além disso, o tipo de tarefa dos dois experimentos requer que o participante engaje em um processamento algorítmico, em que as relações de escopo precisam ser efetivamente consideradas. Dessa forma, pode-se considerar que estes experimentos se aproximam, em certa medida, do experimento 2 de Dwivedi (2013).

Na próxima seção, de modo a poder situar os nossos estudos com Qs no PB, serão mencionados trabalhos que vêm examinando Q-universais a partir de um viés teórico bem como pesquisas com caráter experimental. Em seguida, uma visão geral dos resultados da pesquisa que temos realizado será apresentada.

\section{EXPRESSÕES-Q NO PB: CARACTERIZAÇÃO TEÓRICA E EVIDÊNCIAS EXPERIMENTAIS}

Em termos de análises linguísticas, tem havido consenso na literatura quanto à caracterização teórica de cada no PB como Q-distributivo. O mesmo não se aplica ao $\mathrm{Q}$ todo/todos.

Para Müller et al. (2007), o mesmo item morfológico todo pode carregar traços distintos e tomar tanto um NP singular, quanto um DP singular ou plural como seu argumento, o que derivaria em diferentes interpretações. Assim, todo + NP singular deflagra interpretações distributivas (Toda caneta está num estojo) enquanto todo + DP plural envolveria intepretações predominantemente coletivas (Todas as canetas estão num estojo) e todo + DP singular privilegiaria interpretações adverbiais (Toda a sala está empoeirada). Em

\footnotetext{
${ }^{8}$ Dwivedi (2013, p.2) esclarece que emprega o termo "computação algorítmica” para fazer referência a mecanismos que são sensíveis a propriedades estruturais da sentença.
} 
todos esses contextos, contudo, todo seria um Q-universal distributivo, e uma possível leitura coletiva seria, segundo as autoras, apenas ilusória. As autoras acrescentam ainda que o efeito maximizador (de acordo com o qual o conjunto delimitado pelo $Q$ deve ser exaurido) de todo é um subproduto da distributividade.

Negrão (2002), por sua vez, contrasta o comportamento de cada e de todo + NP singular. A autora afirma que todo teria um comportamento camaleônico e que poderia participar ora de leituras distributivas ora genéricas. Expressões-Q com todo se comportariam no PB como indefinidos (no sentido dado por HEIM, 1982) na medida em que introduziriam uma variável que terminaria selecionada de forma presa por operadores sentenciais de maneira não seletiva - no caso, o operador distributivo ou o operador genérico.

Num trabalho mais recente no âmbito da Semântica Experimental, Lima (2013) analisa o comportamento de todos + DP plural e afirma que este não seria propriamente um Q, mas um modificador que herdaria leituras coletivas ou distributivas do DP plural. Lima sugere que, quando combinado com um DP plural, tod-desencadearia maximalidade enquanto cada seria marcado essencialmente para distributividade.

Com uma visão semelhante, Quadros Gomes (2009) propõe que todo não é um operador canônico como $c a d a$, e sim um modificador - não um modificador nominal, mas um modificador da relação de predicação. De acordo com a autora: "todo modifica quantitativamente a relação entre um predicado e seu argumento, requerendo a participação da extensão completa (subdividida em dois ou mais participantes discretos) do nominal na eventualidade" (p. 198). Assim, enquanto every, em inglês, e cada, em português, criariam relações distributivas entre dois sintagmas, todo seria um modificador de uma relação existente.

Em trabalho mais recente, juntamente com Vicente (2013), Quadros Gomes propõe um tratamento unificado para todo, em que este seria um modificador sentencial disfarçado de determinante, que, em termos estruturais, estaria na posição de especificador de um sintagma de grau, que dominaria um nó bifurcado contendo um predicador e seu argumento.

No que tange a resultados de natureza experimental, relativos à interpretação desses Qs, estes diferem em função do tipo de tarefa e de técnica experimental utilizada. Lopes (2013) verificou, por meio de um questionário off-line, uma preferência pela opção distributiva quando o Q-todo é singular e pela leitura coletiva no plural. Nesse teste, uma sentença contendo uma das expressões-Q investigadas era apresentada juntamente com duas possíveis interpretações (6). Os participantes deviam indicar sua preferência, sendo que mais de uma opção poderia ser selecionada.

(6) Toda menina está em um barquinho/Todas as meninas estão num barquinho

a. ( ) Há 4 meninas e todas elas estão num mesmo barquinho

b. ( ) Há 4 meninas e cada uma delas está em um barquinho distinto

Marcilese e Rodrigues (2012, no prelo, submetido a), por sua vez, por meio de um conjunto de experimentos conduzidos com técnicas diversas, obtiveram resultados que sugerem uma preferência por leituras não distributivas independentemente da configuração sintática do Q-todo (NPs singulares/DPs plurais). Em três experimentos envolvendo seleção de figuras e julgamento de compatibilidade entre sentença/imagem, foi registrado um número significativamente maior de escolhas e julgamentos positivos das imagens coletivas - quando comparado com a eleição da figuras distributivas - bem como tempos de avaliação positiva significativamente menores para as figuras coletivas. No caso da expressão todo $+\mathrm{NP}$, a rejeição das figuras coletivas registrou a maior média dos tempos de reação.

Esses resultados, não podem, contudo, ser tomados como indicativos de uma preferência pela interpretação de Q-todo como sendo associado a leituras coletivas pelo fato de que apenas duas possibilidades eram apresentadas (coletivo/distributivo). Interpretações genéricas e adverbiais não estavam disponíveis para avaliação. Esses resultados podem, no entanto, sinalizar que - na ausência de maiores informações - leituras distributivas não seriam preferencialmente atribuídas a esses sintagmas-Q. Esse resultado pode ser relacionado com o reportado por Frazier, Pacht e Rayner (1999) e Boylan et al. (2012). Nessas pesquisas foi observada uma preferência por leituras coletivas associadas a sentenças potencialmente ambíguas contendo sintagmas coordenados do tipo Sam and Mary carried one suitcase at the airport (Samuel e Maria carregaram uma mala no aeroporto). Os autores postulam a existência de um comprometimento semântico (semantic commitment) na compreensão desse tipo de estruturas que não decorreria de uma interpretação baseada em 
informações puramente estruturais. Em que medida expressões-Q com todo e todos os podem, da mesma forma, apresentar esse tipo de interpretações preferencial é uma possibilidade a ser avaliada.

Ainda na mesma sequência de experimentos (MARCILESE; RODRIGUES, NO PRELO; RODRIGUES; MARCILESE, submetido a), foi conduzida uma tarefa de produção de imagens a partir de sentenças contendo expressões-Q. Nesse caso, enquanto para todo + DP plural houve uma escolha maciça por representações coletivas (86\%), no caso de todo + NP singular o padrão de respostas foi mais heterogêneo. Além de representações coletivas, foram registradas interpretações adverbiais e de objetos únicos. O total de respostas compatíveis com intepretações distributivas aumentou, embora não tenha chegado a representar uma escolha preferencial, atingindo $47 \%$ das respostas.

Rodrigues e Marcilese (submetido b) pesquisaram - a partir de experimentos de leitura automonitorada e de julgamento de gramaticalidade - a retomada anafórica das representações geradas a partir da computação de sentenças contendo expressões-Q. Nos experimentos conduzidos - que contrastaram a interpretação dos $\mathrm{Q}$ cada, todo $+\mathrm{NP}$ e todo $+\mathrm{DP}$ - a retomada de antecedentes por pronomes anafóricos singulares ou plurais foi concebida como uma estratégia para avaliar o tipo de leitura privilegiada para os $Q$ investigados. O número do pronome anafórico foi manipulado, de modo a remeter a representações singulares (compatíveis com leituras coletivas) ou plurais (compatíveis com leituras distributivas) em sentenças do tipo Cada/Todo/Todos/os documento/s estava/m numa pasta e ela/elas foi/foram extraviada/s nos correios. Os tempos de leitura registrados no pronome anafórico, no auxiliar e no particípio foram analisados e os resultados revelaram um padrão diferenciado para cada uma das expressões- $Q$ investigadas. $O$ julgamento das sentenças também foi considerado e revelou uma correlação entre o tipo de expressão-Q, o tipo de julgamento (positivo/negativo) e o tempo de reação. As mesmas sentenças foram utilizadas num experimento de julgamento de gramaticalidade no qual os participantes deviam fazer sua avaliação a partir de uma escala de 1-5 ( $1=$ péssimo, $5=$ perfeito). Os resultados revelaram, mais uma vez, um padrão diferenciado de respostas para cada expressão-Q.

Em conjunto, os resultados sugerem uma preferência forte por leituras distributivas associadas ao Q-cada (embora a rejeição da possibilidade coletiva não tenha sido absoluta) e leituras coletivas sendo as privilegiadas para todo + DP plural. Já no caso de todo + NP singular, os resultados sugerem que se trata de elemento sub-especificado que pode receber leituras compatíveis com interpretações de grupo, adverbiais e genéricas (e, mais raramente, distributivas).

Na tabela 1 (abaixo), sintetizamos os principais resultados obtidos por Marcilese e Rodrigues (2012, a sair) e Rodrigues e Marcilese (submetido a, b). Os resultados sintetizados nessa tabela sugerem que fatores tais como pressão de tempo, natureza do julgamento requerido e objetivos da tarefa, podem afetar a interpretação das expressões-Q. Nesse sentido, escolher uma imagem como adequada para representar uma sentença previamente interpretada ou julgar se uma imagem é compatível com uma interpretação previa implica que o participante já fez uma análise e deverá então contrastar o resultado da mesma com uma ou várias representações visuais. Quando o tempo de resposta é considerado, tempos de reação maiores para rejeitar uma imagem (como os registrados nas imagens coletivas associadas ao Q-todo + NP singular) sugerem que a representação linguística construída não permitiria rejeitar nem aceitar facilmente essa figura. No experimento de produção de imagens, pelo fato de a sentença ficar acessível enquanto os participantes desenhavam e por não haver pressão de tempo mais rígida, processos de avaliação mais conscientes podem ter sido deflagrados. Nesse caso, as respostas para todo + NP singular sugerem que esse elemento não recebe uma única interpretação preferencial, diferentemente do que ocorre com todo + DP que concentrou um número significativamente alto de respostas coletivas. Quando consideramos os resultados dos experimentos nos quais os participantes deviam avaliar uma sentença como sendo aceitável ou inaceitável em termos gramaticais, observamos que, a depender da situação experimental (com/sem pressão de tempo) e das variáveis dependentes avaliadas, surgem diferenças no padrão de respostas. Enquanto no experimento de leitura automonitorada a retomada singular do Q-cada recebeu quase $68 \%$ de aceitação e os tempos de leitura e julgamento não mostraram diferenças entre as condições, o teste de julgamento com escala revelou uma preferência clara por leituras distributivas. Em princípio, pelo fato de ele ser um Q com um traço lexicamente definido, cada deflagraria automaticamente uma leitura distributiva. Note-se, contudo, que quando se tem uma tarefa com pressão de tempo, os participantes parecem proceder a uma leitura superficial. Já todo + DP plural, foi consistentemente associado a leituras coletivas em ambos os tipos de tarefas. Neste caso, embora o $Q$ seja potencialmente ambíguo, os participantes não parecem perceber essa possibilidade. Nesses experimentos, mais uma vez, todo + NP revelou um padrão menos claro e houve 
diferenças quando comparadas as medidas on-line e off-line. Em síntese, tarefas diferentes que envolvem processos e decisões distintas, bem como as medidas comportamentais consideradas, revelam padrões que podem ser analisados como sendo compatíveis com interpretações diferentes das expressões-Q.

Tabela 1 - Síntese dos resultados experimentais obtidos reportados em Marcilese e Rodrigues (2012, a sair) e Rodrigues e Marcilese (submetido a, b)

Tarefa experimental
Seleção de imagens
Escolher, dentre três opções
(distributiva/coletiva/distrator)
a imagem mais compatível com
a sentença previamente lida.

Julgamento de adequação sentença/imagem 1

Avaliar se uma imagem apresentada após a leitura de uma sentença - seria ou não uma representação aceitável da mesma. Ex. Todo canudo está num copo/ Todos os canudos estão num copo

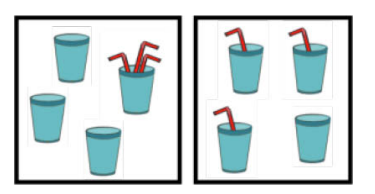

Julgamento de adequação sentença/imagem 2

Experimento idêntico ao anterior, mas os estímulos visuais foram alterados para evitar um efeito de pareamento um-a-um entre os conjuntos no caso das imagens distributivas. Ex. Todo canudo está num copo/

\section{Expressão-Q investigada}

\begin{tabular}{|c|c|c|}
\hline Cada & Todos os & Todo \\
\hline Não avaliado. & $\begin{array}{l}\text { Preferência por } \\
\text { imagens compatíveis } \\
\text { com leituras } \\
\text { coletivas (média de } \\
5 / 6 \text { ) }\end{array}$ & $\begin{array}{l}\text { Preferência por } \\
\text { imagens compatíveis } \\
\text { com leituras } \\
\text { coletivas (média de } \\
4,05 / 6 \text { ) }\end{array}$ \\
\hline
\end{tabular}

Ex. Todo/s (os) lápis está/ão numa caixa

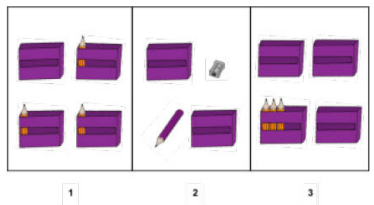

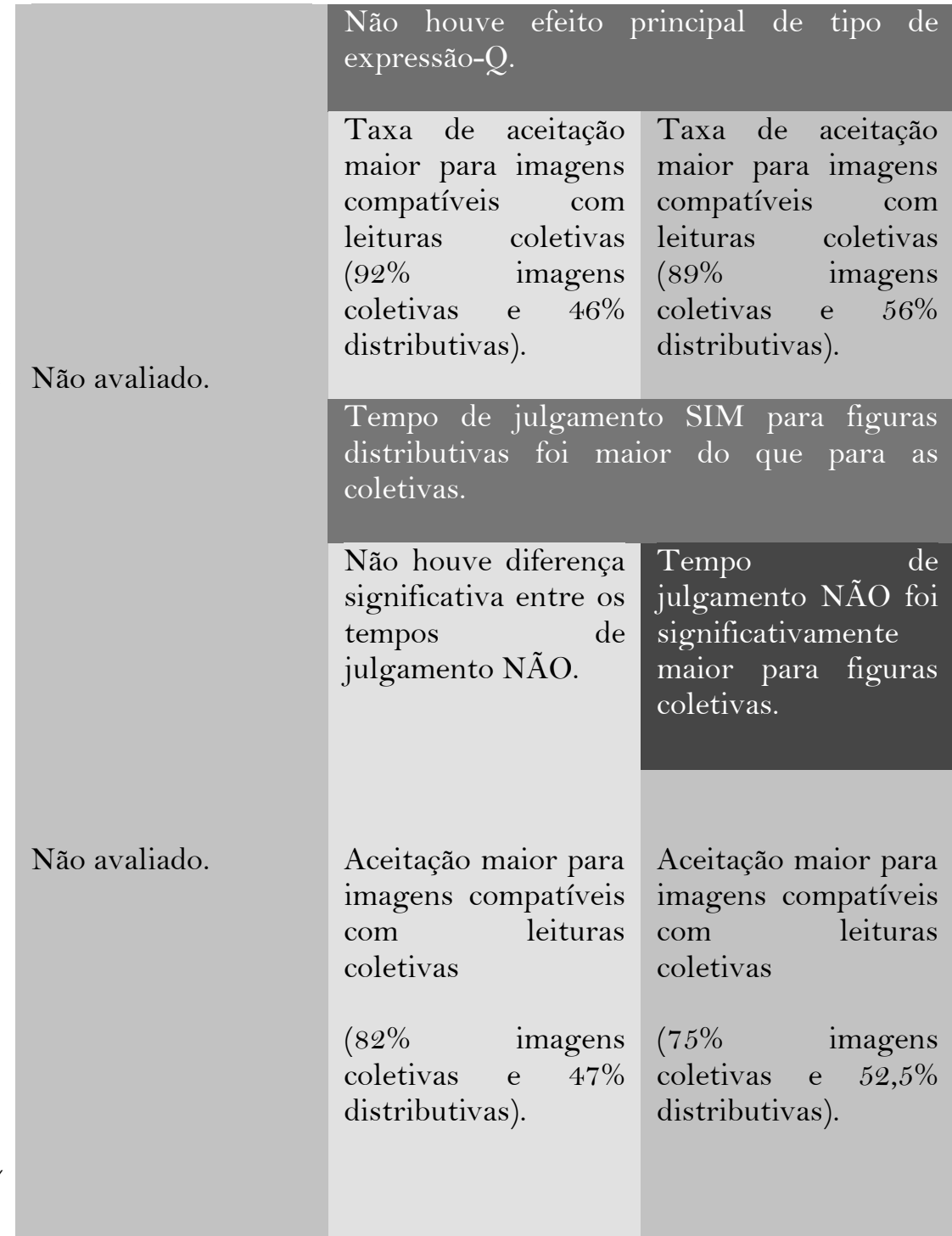


Todos os canudos estão num copo.

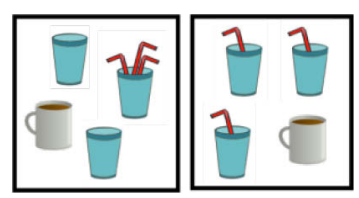

Tarefa de produção de imagens com interpretação livre de sentenças

As sentenças eram apresentadas para os participantes e estes deviam produzir uma representação gráfica relativa à sua interpretação.

Leitura automonitorada

Explorando a correferência anafórica na interpretação de $Q$.

Leitura automonitorada, palavra por palavra, e julgamento da sentença como aceitável (SIM) ou não aceitável (NÃO).

Ex.: $\quad$ Cada/Todo/Todos os funcionários estavam numa van e ela/elas foi/foram detida/s numa blitz.
Não avaliado.

Não

houve diferenças no tempo de leitura entre as condições.

Número

de

julgamentos SIM: pronome singular (leitura coletiva) $=$ 67,75\%; pronome distributiva) $=82 \%$. plural (leitura

Não houve diferença significativa entre os tempos de julgamento SIM.

\section{Não houve diferença significativa entre os tempos julgamento NÃO. \\ de \\ Tempo \\ de \\ julgamento NÃO \\ significativamente \\ maior para figuras coletivas. \\ $86 \%$ de desenhos compatíveis com $13 \%$ de outras genéricas?) respostas e apenas $1 \%$ de $11 \%$ de outras representações respostas e $47 \%$ distributivas. distributivas. \\ A retomada por pronome plural (leitura distributiva) registrou tempos médios significativamente maiores.}

Menor tempo de leitura registrado para a retomada por pronome singular

(leitura coletiva).

Número de Número de julgamentos SIM: julgamentos SIM: pronome singular pronome singular (leitura coletiva $)=($ leitura coletiva $)=$ $91,5 \%$; pronome $47,5 \%$; pronome plural (leitura plural (leitura distributiva $)=25 \% . \quad$ distributiva $)=19 \%$.

Diferença no tempo

Não houve diferença entre as condições no tempo de julgamento SIM/NÃO. de julgamento

Ã O: tempo maior para o julgamento NÃO na retomada por pronome singular (leitura coletiva) e tempo maior para julgamento SIM na retomada por pronome plural 
Julgamento de gramaticalidade (escala de 1 a 5 , sendo 5 o melhor) Questionário off-line e
julgamento das sentenças
utilizando uma escala de $1-5$.

Ex.: $\quad$ Cada/Todo/Todos os funcionários estavam numa van e ela/elas foi/foram detida/s numa blitz.

\begin{tabular}{llrr}
\multicolumn{3}{l}{ Proporção maior de } \\
julgamentos & dos \\
tipos 4 e e & 5 & na \\
condição & & de \\
retomada & & por \\
pronome & & plural
\end{tabular}

Proporção maior de julgamentos de tipo 4 e 5 na condição de retomada por pronome singular (leitura coletiva) o (leitura distributiva), que sugere uma o que sugere uma preferência por preferência pela interpretações interpretação distributiva associada expressão-Q com coletivas associadas à expressão-Q formada por todo + DP plural.
Para retomada pelo pronome singular (leitura coletiva), a proporção de julgamentos 4 e 5 foi pequena.

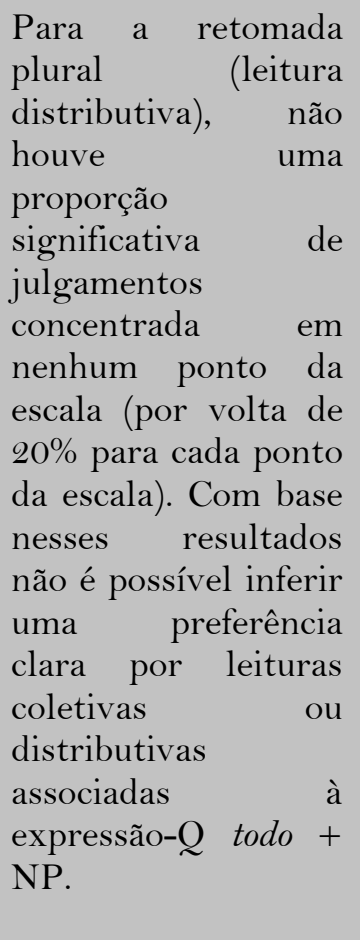

Nos trabalhos conduzidos no $\mathrm{PB}$ e reportados até aqui, contudo, não há nada que, em princípio, restrinja as possíveis leituras das expressões-Q. Apenas a pesquisa de Lima (2013) considerou o papel da presença de um contexto prévio na interpretação. Esse trabalho apresenta, no entanto, algumas limitações pelo fato de que: (i) foram considerados sintagmas-Q com cada e todo + DP plural, mas não todo + NP singular; (ii) o teste conduzido consistiu em um questionário off-line que os participantes realizavam sem qualquer controle de tempo nem supervisão por parte do pesquisador; (iii) o número de participantes foi pequeno demais para permitir qualquer análise estatística.

Os experimentos que reportamos a seguir foram inspirados no trabalho de Lima (2013) e visam a explorar a interpretação de sintagmas- $Q$ com $c a d a$ e $t o d o(s)$ quando essas expressões-Q estão associadas a contextos que favorecem leituras distributivas ou coletivas. O objetivo geral foi avaliar em que medida a presença de um contexto prévio desambiguizador e de uma tarefa de compreensão/julgamento seriam capazes de direcionar a interpretação de sentenças com expressões-Q, inibindo a atuação de procedimentos heurísticos e forçando a implementação de algoritmos baseados na informação lexical contida nos Qs investigados. 


\section{EXPERIMENTOS}

Foram conduzidos dois experimentos visando a avaliar em que medida a presença de um contexto discursivo previamente apresentado poderia forçar leituras distributivas ou coletivas associadas aos Quniversais cada, todo e todos os. O primeiro experimento foi conduzido com base numa tarefa de leitura automonitorada e envolveu o controle do tempo de apresentação dos estímulos e o registro dos tempos de resposta dos participantes. Para o Experimento 2 foi utilizado um questionário e, embora os tempos de resposta não tenham sido mensurados, os participantes deviam realizar a tarefa dentro de um período de tempo e em condições semelhantes.

\subsection{Experimento 1: julgamento de expressões- $Q$ a partir de contexto discursivo prévio}

\section{Método}

As variáveis independentes foram contexto (coletivo/distributivo, fator within-subjects) e expressão- $Q$ (cada/todo/todos os, fator between-subjects). As variáveis dependentes foram o tempo de reação (TR, envolvendo leitura e julgamento das sentenças) e o número de julgamentos (positivos ou negativos, S/N) por condição.

\section{Participantes}

Participaram do experimento 42 estudantes universitários falantes nativos de PB, dos quais 29 mulheres e 13 homens. A participação foi voluntária e os sujeitos não receberam qualquer tipo de gratificação pela sua colaboração.

\section{Materiais e procedimento}

Foram construídos contextos discursivos favoráveis a interpretações coletivas ou distributivas (cinco por condição) e sentenças-alvo contendo as expressões-Q investigadas. Foram utilizados ainda 20 contextos/sentenças distratoras (cf. Exemplos na Tabela 2).

Tabela 2 - Exemplos das condições experimentais e distratores empregados

\begin{tabular}{|c|c|c|}
\hline Contexto Coletivo & Contexto Distributivo & Contexto Distrator \\
\hline $\begin{array}{l}\text { Helena adora comprar roupas. } \\
\text { Assim que recebe o salário, } \\
\text { corre para o shopping, mas seu } \\
\text { guarda-roupas é pequeno e ela } \\
\text { precisa juntar várias roupas } \\
\text { em um só cabide. Foi isso o } \\
\text { que fez com as calças novas } \\
\text { que comprou ontem. }\end{array}$ & $\begin{array}{l}\text { Pedro trabalha numa lavanderia e se } \\
\text { ocupa de organizar as roupas limpas e } \\
\text { passadas. Hoje ele preparou o pedido } \\
\text { de um hotel que entrega as toalhas de } \\
\text { banho para seus hóspedes em } \\
\text { saquinhos plásticos individuais } \\
\text { personalizados. Pedro dobrou e } \\
\text { embalou as toalhas do hotel. }\end{array}$ & $\begin{array}{l}\text { Paulo trabalha numa } \\
\text { confeitaria. Hoje ele ficou } \\
\text { trabalhando num pedido para } \\
\text { uma festa de casamento. Além } \\
\text { do bolo principal, ele preparou } \\
\text { dois bolos simples de } \\
\text { chocolate e três de baunilha } \\
\text { com chantilly e morangos. }\end{array}$ \\
\hline Frases-alvo & Frases-alvo & Frase-alvo \\
\hline $\begin{array}{l}\text { Cada calça nova estava num } \\
\text { cabide de madeira. }\end{array}$ & $\begin{array}{l}\text { Cada toalha estava num saquinho } \\
\text { plástico. }\end{array}$ & $\begin{array}{l}\text { Nenhum dos bolos de } \\
\text { chocolate tinha recheio. }\end{array}$ \\
\hline $\begin{array}{l}\text { Toda calça nova estava num } \\
\text { cabide de madeira. }\end{array}$ & $\begin{array}{l}\text { Toda toalha estava num saquinho } \\
\text { plástico. }\end{array}$ & \\
\hline $\begin{array}{l}\text { Todas as calças novas estavam } \\
\text { num cabide de madeira. }\end{array}$ & $\begin{array}{l}\text { Todas as toalhas estavam num } \\
\text { saquinho plástico. }\end{array}$ & \\
\hline
\end{tabular}

Os contextos discursivos eram apresentados na tela do computador por 20 segundos. Os participantes foram orientados a ler o contexto e avançar apertando a barra espaçadora do teclado. Em seguida, uma 
sentença-alvo era apresentada. A tarefa do participante consistia em ler essa frase e avaliar em que medida ela era compatível com a informação previamente apresentada. Para isso, o participante devia apertar uma das duas teclas destacadas como SIM/NÃO. Durante a fase de treinamento, os participantes receberam a orientação de realizar o julgamento o mais rapidamente possível. O tempo de leitura/julgamento foi registrado para posterior análise, bem como a escolha feita pelo participante. $O$ experimento foi programado e executado utilizando o software Psyscope e aplicado em computadores MacBook Air.

\section{Resultados}

Os dados foram submetidos à análise estatística em função das duas variáveis dependentes estabelecidas. A primeira variável considerada foi o TR. Uma análise da variância $(2 \mathrm{X} 2$ - contexto $x$ expressão-Q) não revelou qualquer efeito significativo. No entanto, quando os tempos de reação foram separados em virtude do tipo de julgamento (S/N) atribuído em cada caso, surgiram efeitos significativos relevantes.

Embora o Q-cada tenha registrado tempos maiores para a rejeição da condição distributiva, isto é, a única que seria compatível com essa expressão-Q, a diferença no TR entre os julgamentos $\mathrm{S} / \mathrm{N}$ nessa condição não foi estatisticamente significativa $(\mathrm{t}(13)=1.32 \mathrm{p}=0.1)$.

Gráfico 1 - Tempo médio de resposta para as expressões-Q com cada em função do contexto e do tipo de julgamento

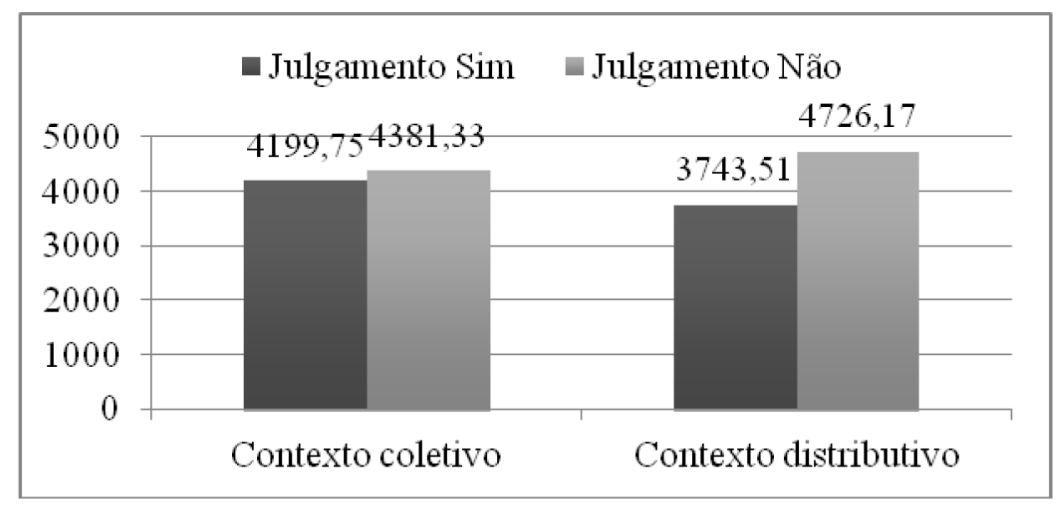

No que diz respeito ao Q-todo, a análise estatística revelou que a rejeição do contexto coletivo foi significativamente mais lenta $(\mathrm{t}(13)=2.68 \mathrm{p}=0.009)$. Já no contexto distributivo, não houve diferença no TR quando comparados os julgamentos $\mathrm{S} / \mathrm{N}$.

Gráfico 2 - Tempo médio de resposta para as expressões-Q com todo em função do contexto e do tipo de julgamento

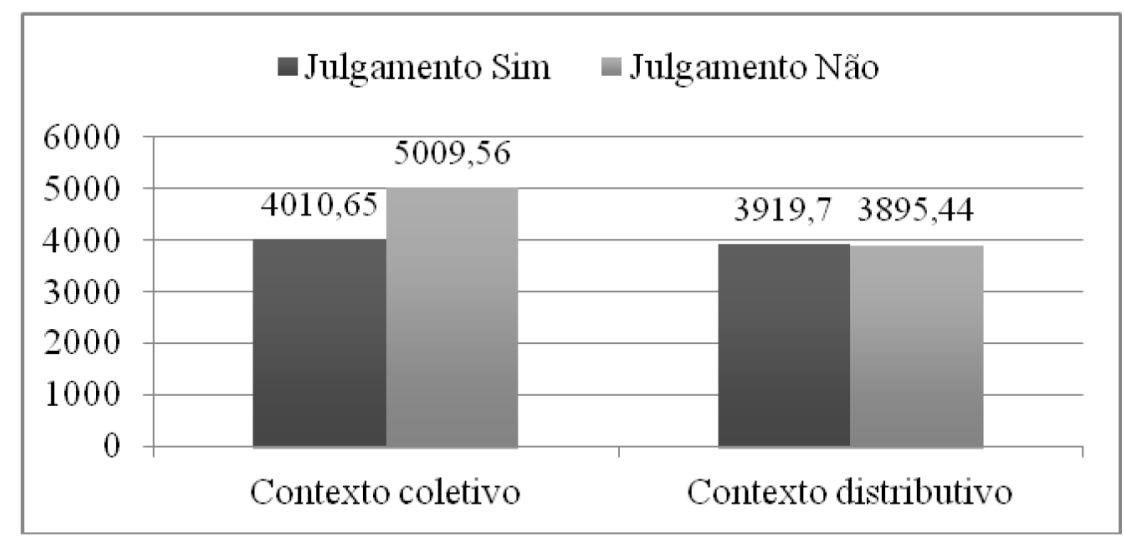

A análise dos resultados relativos à expressão-Q com todos os revelou que, em ambos os contextos, o julgamento negativo registrou TR significativamente maiores do que o verificado para o julgamento 
positivo (Comparação entre $\mathrm{S} / \mathrm{N}$ no contexto coletivo $(\mathrm{t}(13)=1.84 \mathrm{p}=0.04)$ ), Comparação entre $\mathrm{S} / \mathrm{N}$ no contexto distributivo $(\mathrm{t}(13)=3.63 \mathrm{p}=0.001))$.

Gráfico 3 - Tempo médio de resposta para as expressões-Q com todo os em função do contexto e do tipo de julgamento.

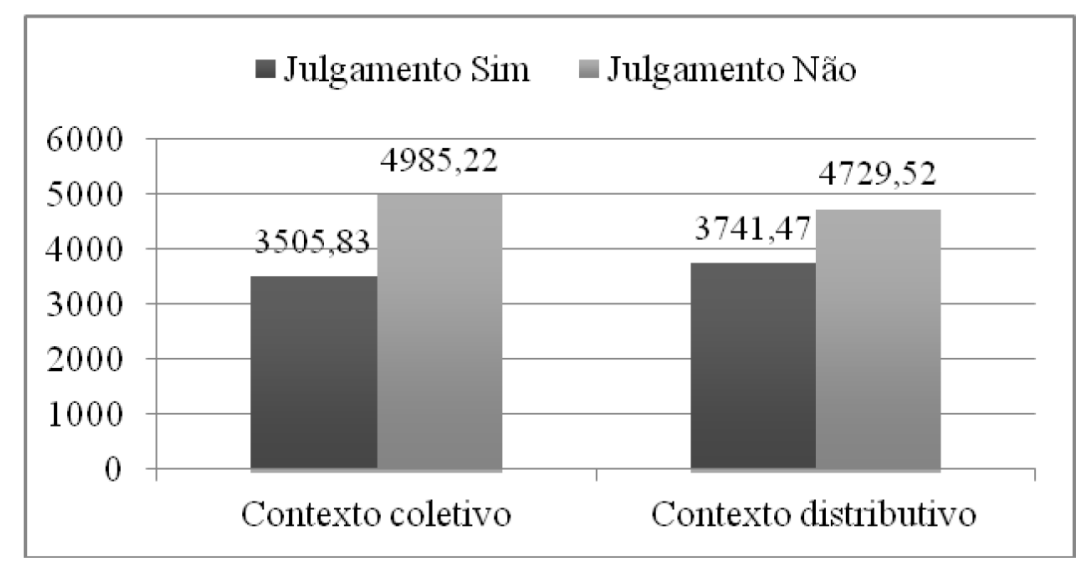

Quando considerada a variável dependente número de julgamentos $\mathrm{S} / \mathrm{N}$ por condição (Max Score =5), cada registrou um número significativamente maior de julgamentos positivos no contexto distributivo. No caso de todo, o total de julgamentos positivos foi maior no contexto distributivo apenas na análise unicaudal $(\mathrm{p}<0,042)$. Para todos os, não houve diferença entre os contextos.

Gráfico 4 - Média de julgamentos S/N em função de contexto e tipo de expressão-Q

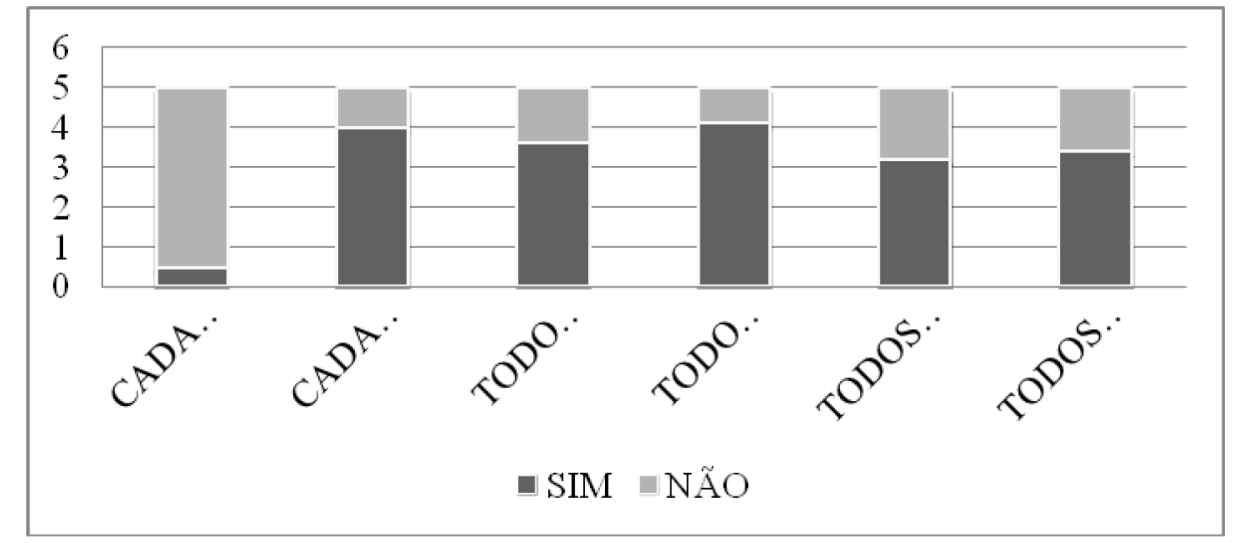

\subsection{Experimento 2: Ranking de expressões-Q a partir de contexto discursivo prévio}

\section{Método}

A variável independente foi contexto (coletivo/distributivo, fator between-subjects). As variáveis dependentes foram o julgamento e o ranking de sentenças (quando mais de uma sentença era avaliada como sendo aceitável, os participantes deviam ranquear suas respostas).

\section{Participantes}

Participaram 44 estudantes universitários falantes nativos de PB, 32 mulheres e 12 homens. A participação foi voluntária e os sujeitos não receberam qualquer retribuição pela sua colaboração. 


\section{Materiais e procedimento}

Foram utilizados os mesmos contextos/sentenças-alvo empregados no Experimento 1, mas neste caso não foram incluídos contextos e sentenças distratoras. O experimento consistiu de um questionário no qual era apresentado o contex to (coletivo ou distributivo) seguido de três sentenças (cada uma delas correspondendo a um das expressões-Q investigadas, cf. Tabela 3). A tarefa do participante era escolher a sentença mais adequada em virtude do contexto prévio. Mais de uma sentença poderia ser escolhida e, nesse caso, o participante deveria indicar a ordem de preferência, se houvesse. Caso o participante julgasse duas ou mais sentenças como sendo igualmente adequadas, a orientação foi de indicar isso da seguinte forma: $1^{\circ} \mathrm{A} / \mathrm{B} / \mathrm{C}$, $2^{\circ}$ , $3^{\circ}$

Tabela 3 - Exemplo do questionário utilizado

Miguel coleciona moedas e notas antigas desde os nove anos de idade. No entanto, ele nunca foi muito organizado e tinha as notas, principalmente, espalhadas por vários cantos da casa. Ontem ele comprou uma pasta catálogo e arrumou as notas nela.
A. Cada nota estava numa pasta catálogo
B. Toda nota estava numa pasta catálogo
C. Todas as notas estavam numa pasta catálogo

Ordem de preferência (da mais preferida para a menos preferida): $1^{\circ}$ , $2^{\circ}$ , $3^{\circ}$

\section{Resultados}

$\mathrm{Na}$ análise dos resultados foi considerado tanto o número absoluto de julgamentos positivos para cada tipo de expressão- $Q$ em cada um dos dois contextos avaliados (coletivo/distributivo) quanto o ranking de aceitação por condição. O gráfico 5 mostra o número de escolhas de cada um dos Qs no contexto coletivo, indicando quando essas escolhas corresponderam à primeira, segunda ou terceira opção dos participantes. Note-se que, no contexto coletivo, todo + DP plural foi a expressão-Q mais escolhida como primeira opção, seguida por todo $+\mathrm{NP}$, mas com um número muito pouco expressivo de escolhas. Cada, por sua vez, nunca foi a primeira opção. Como segunda opção, os participantes preferiram todo + NP singular e, como terceira - com um número bastante reduzido de escolhas - cada.

Gráfico 5 - Número e ranking de escolhas de cada expressão-Q no contexto coletivo

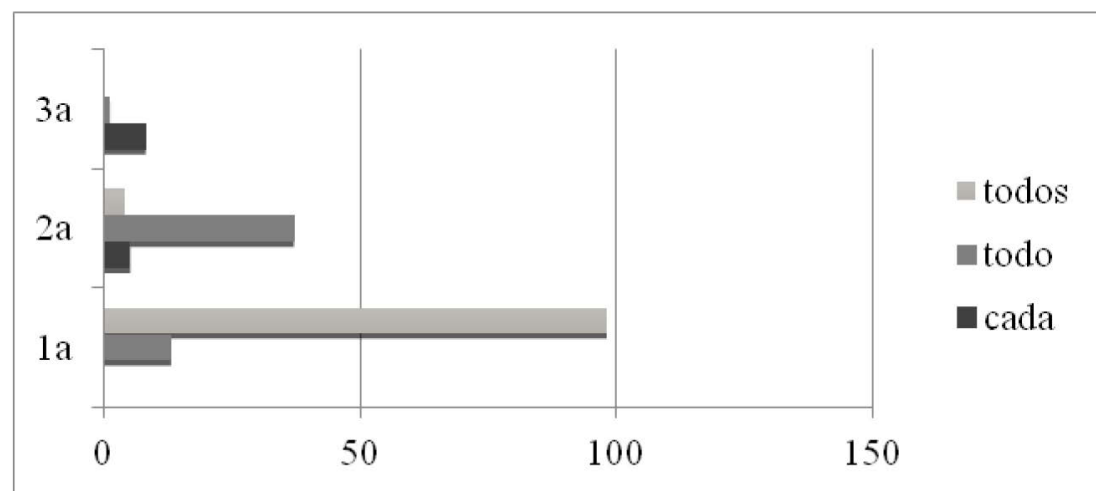

O gráfico 6 apresenta os resultados do contexto distributivo. Neste caso, cada registrou uma preferência clara, sendo escolhido como primeira opção. Ainda dentro da escolha como primeira melhor opção, os participantes preferiram todo + NP, seguido de todo + DP plural. Como segunda melhor opção, os participantes preferiram todo + DP plural. Note-se que, embora todos os possa em princípio receber tanto 
leituras coletivas quanto distributivas, quando os participantes são confrontados com as três possibilidades, depois do Q-cada, a expressão-Q com todo + NP singular é preferida.

Gráfico 6 - Número e ranking de escolhas de cada expressão-Q no contexto distributivo

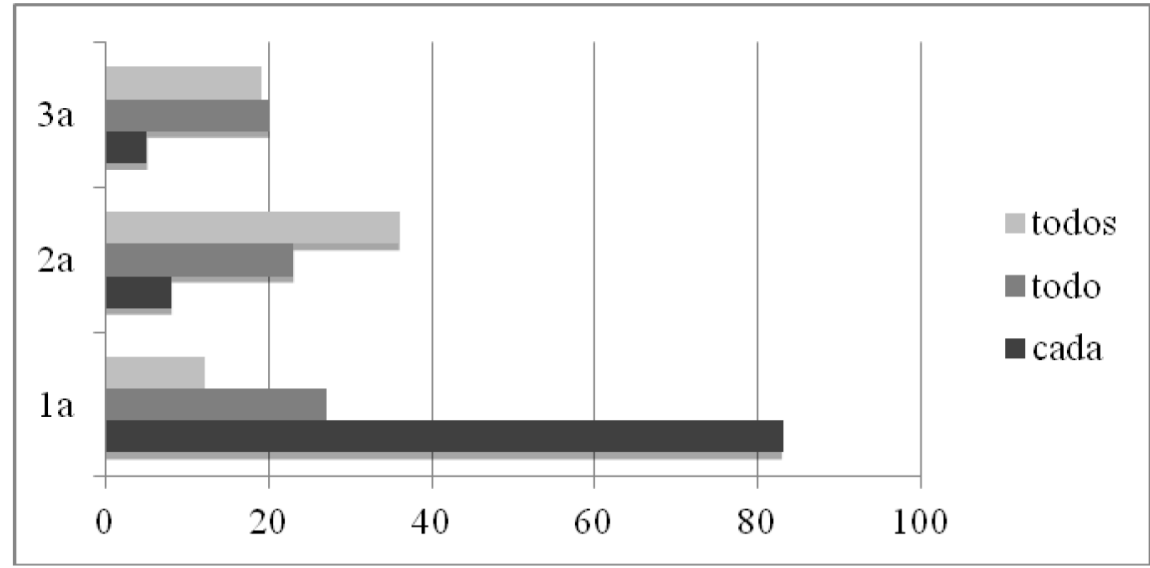

\subsection{Discussão dos resultados experimentais}

Os resultados sustentam a caracterização de cada como Q-distributivo, com uma preferência clara por contextos desse tipo, tal como verificado por Lima (2013). No caso de todos os, este foi aceito em ambos os contextos, com tempos de reação semelhantes. Esse resultado contrasta com o obtido em estudos prévios (MARCILESE; RODRIGUES, no prelo e submetido a e b), em que, na ausência de um contexto prévio, a leitura coletiva foi preferida de forma maciça. A presença de um contexto (bem como a própria tarefa de avaliação da sentença) parece ter sido capaz de inibir a leitura coletiva preferencial - observada nos estudos anteriores - e forçado os participantes a perceber a potencial ambiguidade dessa expressão-Q. Note-se que foram registrados TR maiores para os julgamentos NÃO, independentemente da condição experimental, o que sugere que a rejeição das sentenças representou um conflito para os participantes. Esse resultado é compatível com o fato de que ambas as leituras são, efetivamente, possíveis.

Não foi verificada uma preferência clara por leituras distributivas associadas ao Q-todo. No entanto, diferentemente do registrado nos experimentos prévios, os participantes aceitaram tanto leituras coletivas quanto distributivas para esse tipo de expressão-Q. Os tempos de reação registrados no experimento 1 sugerem, no entanto, uma maior dificuldade para a rejeição da interpretação coletiva. Em síntese, os resultados registrados para todo + NP singular se mostram compatíveis com a ideia de Negrão (2002) de que se trata de um elemento de natureza indeterminada.

\section{CONSIDERAÇÕES FINAIS}

Tomados em conjunto, os resultados obtidos até o momento sugerem que o uso de diferentes técnicas experimentais pode permitir captar níveis distintos do processamento linguístico. O que é solicitado em cada tipo de tarefa pode levar o participante a se engajar em um modo de processamento distinto (de caráter mais algorítmico ou heurístico), o que pode requerer uma análise mais ou menos superficial dos estímulos linguísticos, com reflexos no tipo de leitura preferencial atribuída à expressão-Q.

Nos experimentos aqui reportados, é possível que o contexto prévio bem como o tipo de tarefa solicitada, tenham levado os participantes a realizarem uma análise mais profunda dos estímulos, o que requer uma computação algorítmica, na qual relações de escopo precisam ser efetivamente avaliadas.

Os resultados do conjunto de experimentos realizados até o momento são compatíveis com a hipótese de que o sistema de compreensão da linguagem faz uso de um misto de heurísticas e algoritmos sintáticos. Como esses processos se coordenam exatamente, ainda é um ponto em aberto. A escolha do tipo de tarefa bem como do método usado para avaliação dessa questão se apresenta certamente como crucial. 


\section{REFERÊNCIAS}

BEVER, T. G. The cognitive basis for linguistic structures. In: HAYES, R. (Ed.). Cognition and language development. New York: Wiley \& Sons, Inc., 1970. p. 279-362.

BOYLAN, C. et al. The collective bias? Using eye movements to examine collective vs. distributive interpretations of plural sets. Paper presented at the CUNY CONFERENCE, 2012.

CHRISTIANSON, K. et al. Thematic roles assigned along the garden path linger. Cognitive Psychology, v. 42, n. 4, p. 368-407, 2001.

CRAIN, S. et al. Quantification without qualification. Language acquisition, v.3, n.2, p. 83-153, 1996.

DIETRICH, E. Algorithm. In: WILSON, Robert A.; KEIL, Frank C. (Eds.). The MIT Encyclopedia of the Cognitive Sciences. Cambridge, Massachusetts; London, England: MIT Press, 1999.

DWIVEDI, V. D. Interpreting quantifier scope ambiguity: evidence of heuristic first, algorithmic second processing. PLOS One, v.18, n.11, 2013. $109,2010$.

; et al. The neural underpinnings of semantic ambiguity and anaphora. Brain research, v. 1311, p. 93-

FERREIRA, F. The misinterpretation of noncanonical sentences. Cognitive Psychology, v.47, n.2, p.164-203, 2003.

; BAILEY, K. G. D; FERRARO, V. Good-enough representations in language comprehension. Current directions in psychological science, v. 11, n.1, p. 11-5, 2002.

; PATSON, N. The 'Good enough' approach to language comprehension. Language and linguistics compass, v.1, n.1-2, p.71-83, 2007.

FISCHHOFF, B. Judgments Heuristics. In: WILSON, Robert A.; KEIL, Frank C. (Eds.). The MIT Encyclopedia of the Cognitive Sciences. Cambridge, Massachusetts; London, England: MIT Press, 1999.

FRAZIER, L. On comprehending sentences: syntactic parsing strategies. Connecticut: University of Massachusetts. Indiana University Linguistics Club. Doctoral Dissertation, 1979.

1978.

; FODOR, J. D. The sausage machine: a new two-stage parsing model. Cognition, v. 6, p. 291-326,

; RAYNER, K. Making and correct errors during sentence comprehension: eye movements in the analysis of structurally ambiguous sentences. Cognitive Psychology, v. 14, p.178-210, 1982.

; PACHT, J.; RAYNER, K. Taking on semantic commitments, II: collective versus distributive readings. Cognition, v.70, p. 87-104, 1999.

GILLEN, K. The Comprehension of doubly quantified sentences. Doctoral Dissertation. University of Durham, 1991.

HEIM, I. The semantics of definite and indefinite noun phrases. Ph. D. Dissertation. Amherst: University of Massachusetts, 1982.

KIM, A.; OSTERHOUT, L. The independence of combinatory semantic processing: evidence from eventrelated potentials. Journal of memory and language, v. 52, p. 205-25, 2005.

KURTZMAN H.S.; MacDONALD, M. C. Resolution of quantifier scope ambiguities. Cognition, v. 48, p. 243-279, 1993.

KUTAS, M.; HILLYARD, S. A. Reading senseless sentences: brain potentials reflect semantic incongruity. Science, v. 207, p. 203-205, 1980.

; HILLYARD, S. A. Event-related brain potentials to grammatical errors and semantic anomalies. Memory and cognition, v.11, n.5, p. 539-550, 1983.

LIMA, S. Maximality and distributivity in Brazilian Portuguese. Revista Linguística, Rio de Janeiro, v. 9, n.1, junho de 2013. 
LOPES, R.E.V. Quantifiers in a nominal agreement language: acquisitional cues. In: STAVRAKAKI, S.; KONSTANTINOPOULOU, P.; LALIOTI, M. (Eds.). Advances in Language acquisition. Newcastle: Cambridge Scholar Publishing, 2013.

MARCILESE, M.; RODRIGUES, E. dos S. The interpretation of the Brazilian Portuguese quantifier todo in distributive and collective contexts: an experimental study. In: TORRENS, V.; ESCOBAR, L. The Processing of lexicon and morphosyntax. Cambridge University Press, no prelo.

; RODRIGUES, E. dos S. A compreensão do quantificador universal todo no PB: avaliação da interferência de fatores visuais no processamento In: JORNADA DO GRUPO DE ESTUDOS LINGUÍSTICOS DO NORDESTE - GELNE, 24., 2012, Natal. Anais... Natal: EDUFRN, 2012.

MUlLER, A. L. de P.; NEGRÃO, E. V.; QUADROS GOMES, A. P. . "Todo" em contextos coletivos e distributivos. DELTA. - Documentação de Estudos em Lingǘstica Teórica e Aplicada, v. 23, n. 1, p. 71-95, 2007.

NEGRÃO, E. Distributividade e genericidade nos sintagmas introduzidos por cada e todo. Revista do GEL, número especial, p. 187- 204, 2002.

PHILIP, W. Event quantification in the acquisition of universal quantification. Doctoral Dissertations, University of Massachusetts, Amherst, MA, 1995.

PHILLIPS, C. Parser-grammar relations: We don't understand everything twice. In: SANZ, M.; LAKA, I.; TANENHAUS, M. (Eds.). Language down the garden path: the cognitive and biological basis for linguistic structure. (Papers in honor of Thomas G. Bever). New York: Oxford University Press, 2012.

QUADROS GOMES, A. P. O efeito grau máximo sobre os domínios: como todo modifica a relação argumento-predicado. Tese (Doutorado em Linguística) - Faculdade de Filosofia, Letras e Ciências Humanas, Universidade de São Paulo, São Paulo, 2009.

RAYNER, K et al. The effect of plausibility on eye movements in reading. Journal of experimental Psychology: learning, memory, \& cognition, v. 30, p.1290-301, 2004.

RIBEIRO, Antonio João Carvalho. Late closure e good-enough no processamento de frases garden-path do português do Brasil: evidências de eyetracking. ReVEL, v. 10, n. 18, 2012.

RODRIGUES, E. dos S.; MARCILESE, M. Como os falantes interpretam o quantificador todo no PB? Novas evidências experimentais a partir de uma tarefa de produção de figuras. In: CONGRESSO INTERNACIONAL DA ABRALIN, 2013. Anais...

; MARCILESE, M. Correferência anafórica e interpretação de quantificadores universais. Cadernos de Letras, UFF, submetido b.

ROEPER, T.; STRAUSS, U.; ZURER PEARSON, B. The acquisition path of the determiner quantifier every: Two kinds of spreading. In: HEIZMANN, T. (Ed.). Papers in Language acquisition. University of Massachusetts Occasional Papers UMOP, 34. Amherst, MA: GLSA, 2006.

TOWSEND, D. J.; BEVER, T. G. Sentence comprehension. The integration of habits and rules. MIT Press, 2001.

TUNSTALL, S.L. The interpretation of quantifiers: semantics and processing. Unpublished doctoral dissertation. University of Massachusetts, Amherst, 1998.

TVERSKY, A.; KAHNEMAN, D. Belief in the "law of small numbers." Psychological Bulletin, v.76, p. 105$110,1971$.

; KAHNEMAN, D. Judgment under Uncertainty: Heuristics and Biases. Science, v. 185, n.4157, p.

1124-1131, 1974.

VICENTE, Helena da Silva Guerra; QUADROS GOMES, Ana Paula. Um tratamento unificado de grau para o quantificador flutuante e o intensificador todo. Revista LinguíStica, Rio de Janeiro, v. 9, n. 1, p. 112132 , junho de 2013.

Recebido em 12/07/2014. Aprovado em 28/09/14. 